\title{
Advances and Frontiers in Primate Seed Dispersal
}

\author{
Onja H. Razafindratsima ${ }^{1}$ (D) Hiroki Sato ${ }^{2}$. \\ Yamato Tsuji ${ }^{3} \cdot$ Laurence Culot $^{4}$
}

Received: 7 May 2018 / Accepted: 11 May 2018/Published online: 26 June 2018

(C) Springer Science+Business Media, LLC, part of Springer Nature 2018

\begin{abstract}
Primates play important roles as seed dispersers in many tropical ecosystems, such that studies of their seed dispersal services and impacts have gained interests among primatologists and ecologists in the past few decades. In this article, we first report that the number of scientific publications on primate seed dispersal has increased rapidly over the past 20 years, based on an extensive literature review. These publications encompass diverse primate taxa from the four geographic regions where they naturally occur. We then summarize the contributions to this Special Issue, which reflect on these progresses. Finally, we provide new directions for the next decade.
\end{abstract}

Keywords Frugivore $\cdot$ Tropical forests $\cdot$ Pre-dispersal $\cdot$ Post-dispersal $\cdot$ Fruit removal . Seed fate

For many angiosperms, seed dispersal by frugivorous animals is a key process for seed movement to new environments, species survival, and regeneration (Howe and Smallwood 1982; Terborgh et al. 2002; Wang and Smith 2002). Primates are considered one of the main seed dispersal agents in tropical forest ecosystems because they constitute a large proportion of the frugivore biomass in the tropics (Chapman 1995; Eisenberg and Thorington Jr. 1973). Their contribution to seed dispersal, and ultimately to plant survival and forest structure, has been studied since the 1980s. In 1998, the journal American

Handling Editor: Joanna M. Setchell

Onja H. Razafindratsima

onja@ ricealumni.net

1 Department of Biology, College of Charleston, Charleston, SC 29414, USA

2 Graduate School of Asian and African Area Studies, Kyoto University, Kyoto 606-8501, Japan

3 Department of Ecology and Social Behavior, Primate Research Institute, Kyoto University, Inuyama, Aichi 4840094, Japan

4 Laboratory of Primatology, Department of Zoology, Institute of Biosciences, São Paulo State University, Rio Claro 13506-900, Brazil 
Journal of Primatology published a Special Issue on primate seed dispersal, introducing progress in this research area at that time (Garber and Lambert 1998) (Fig. 1). Twenty years have passed since that milestone, and technological innovations, new theories, and a shift from species-based to community-based approaches in seed dispersal study have influenced primatologists and the study of primate seed dispersal. Now is the time to reflect on the progress of studies on primate seed dispersal over the past two decades, and identify patterns and directions for the next decade.

This Special Issue stems from a general interest among researchers who presented their work on primate seed dispersal at the symposium titled "Advances and Frontiers in Primate Seed Dispersal," organized by Yamato Tsuji and Hiroki Sato, at the joint meeting of the International Primatological Society and the American Society of Primatologists in Chicago, Illinois, USA in August 2016. This issue presents research papers and reviews that illustrate different aspects of seed dispersal by primates, from pre- to post-dispersal phases (Fig. 1). It brings together a collection of articles that extend our knowledge of primate seed dispersal globally (from Africa, Asia, Madagascar, and Neotropics), review what is known, and identify commonalities across geographic locations, intercontinental and taxonomic differences, and gaps in our understanding of primate seed dispersal.

\section{Predispersal}

- evolution of traits* $*$

- primate olfaction \& fruit odor*

- primate vision \& fruit color*

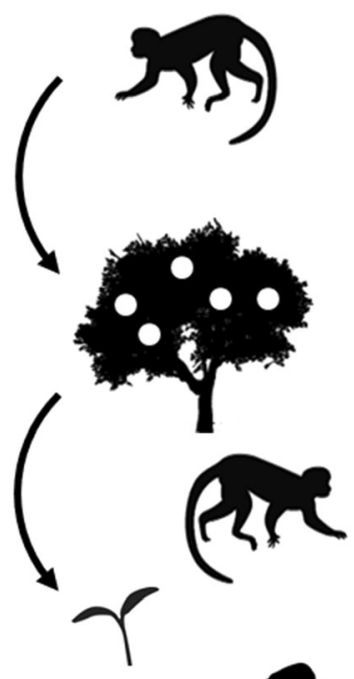

\section{Postdispersal}

- seed fate ${ }^{*} \neq$

- community structure ${ }_{\neq}^{*}$

- impacts on ecosystem*

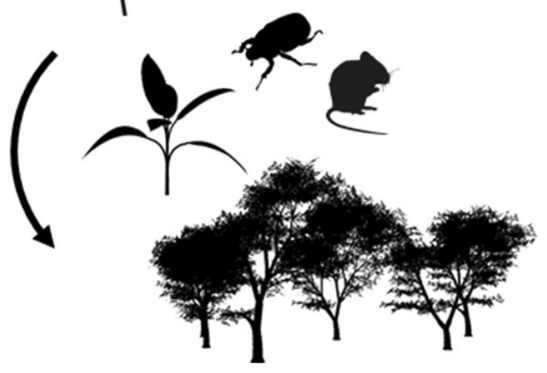

Fig. 1 An illustration of the different aspects of seed dispersal by primates, highlighting the components of each phases presented in this issue (*) and/or in the Special Issue published in 1998 in American Journal of Primatology (キ) 
In this editorial, we first review the literature to identify the trend in the number of publications on primate seed dispersal over time and across geographical regions to provide a context to the contributions. We then introduce each contribution to this Special Issue and conclude with reflections on the current and future state of research on this field.

\section{Publications on Primate Seed Dispersal}

We searched the literature for publications reporting primate seed dispersal, using the Web of Science ${ }^{\mathrm{TM}}$ database, covering articles published from 1979 to December 2017 (accessed January 22, 2018). We used the key words "primate" and "seed dispers*" in our search. We included full-length research articles, short communications, and commentaries, but excluded reviews and studies published as abstracts only. We did not include contributions to edited volumes; those in journals and newsletters published by the IUCN/SSC Primate Specialist Group, which are not indexed by Web of Science; and gray literature. We examined only research papers published in English. We selected articles that discuss any aspect of seed dispersal by any primate taxa as their primary focus, and excluded those that mention primate seed dispersal to support other claims. Our search returned 358 publications that potentially met our criteria; though this review presents valuable information, it is not intended to be exhaustive. Based on these data, published research on primate seed dispersal has increased rapidly in the past 20 years (Fig. 2a), encompassing diverse primate taxa from the four geographic regions where primates occur naturally (Fig. 2b).

\section{Contributions to this Special Issue}

For this Special Issue, we attempted to include studies from the four geographic regions of primate natural habitat: Africa, Asia, Madagascar, and Neotropics. This issue
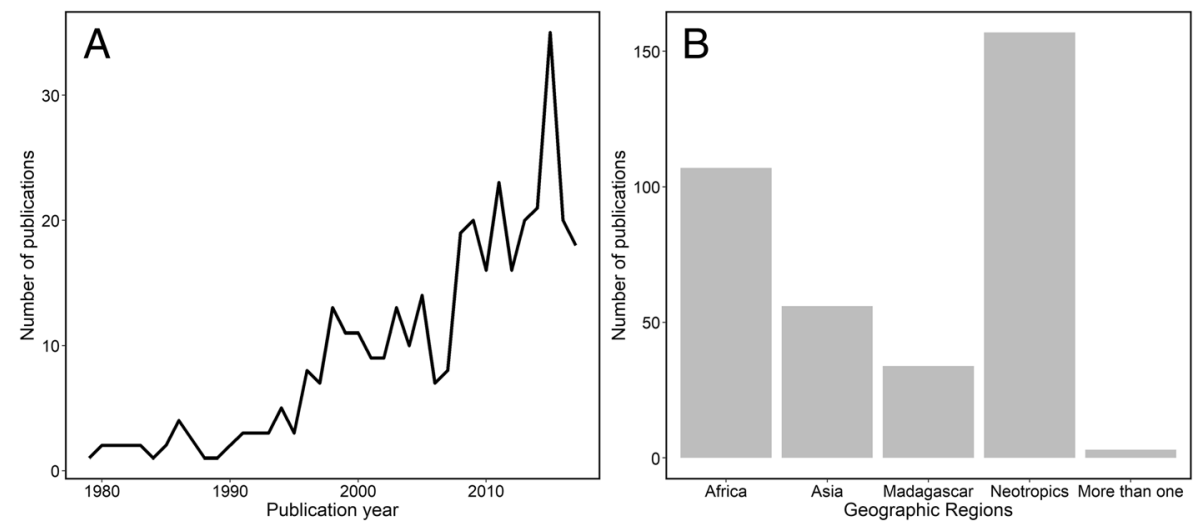

Fig. 2 (a) Number of published research articles on primate seed dispersal from 1979 to December 2017 and (b) number of research articles on primate seed dispersal in the four geographic regions where primates naturally occur, published during that time period (key words: "primate" and "seed dispers*" using the Web of Science ${ }^{\mathrm{TM}}$ database) 
presents research articles and reviews for various primate species, addressing different aspects of seed dispersal, from pre-to post-dispersal phases (Fig. 1). At the pre-dispersal phase, Nevo and Valenta (2018) review the ecology and evolution of fruit odor as related to primate olfaction, which may influence primate fruit selection behavior and ultimately their seed dispersal services. Valenta et al. (2018) provide an overview of how fruit color influences primate selection for fruits, discussing methodological advances in the field of sequencing, spectrometry, and modeling to identify and interpret the linkages between fruit color and primate selection of fruits. At the dispersal phase, Tsuji and $\mathrm{Su}$ (2018) review knowledge of the collective traits that define the role of macaques as seed dispersers in Asian regions. Sato (2018) shows a temporal change in seed dispersal distances in lemurs with respect to behavioral changes for coping with the remarkable seasonality in Madagascar. Finally, at the post-dispersal phase, Culot et al. (2018) show how the characteristics of primary seed dispersal by one mixed-species group of tamarin species (Saguinus mystax and Leontocebus nigrifrons) affect seed burial by dung beetles and seed/seedling survival, and show that seed burial increases dispersal effectiveness more strongly in secondary than primary forest. Razafindratsima et al. (2018) report that losing lemur seed dispersers may result in a decrease of the potential of a Malagasy rainforest to store carbon. This Special Issue also presents work that review and summarize what researchers have accomplished in the past 20 years in several regions in terms of primate seed dispersal, with detailed recommendations for future studies (Andresen et al. 2018; Chapman and Dunham 2018; McConkey 2018). Together, these articles highlight recent advances in the field of primate seed dispersal, including new perspectives on our understanding of the importance of primate frugivores for forest ecosystems at multiple spatial and ecological scales, and the consequences of primate decline and loss for forest integrity and human well-being.

\section{Future Directions}

Although there has been an increase in our knowledge and understanding of the nature, mechanism, and impacts of seed dispersal by primates at multiple scales, further studies are needed. In the last decades, researchers have gathered an impressive amount of data about the role of primates as seed dispersers. However, a gap in knowledge still exists on the relative role of primates compared to other frugivores. It is thus urgent to include primates in studies of plant-animal networks (see McConkey and Brockelman 2011) to better assess their importance and specific roles within the frugivore community. Of course, compiling plant-animal interactions in highly diverse environments such as tropical and subtropical forests is a challenging task. However, the increased availability of datasets in open-access repositories and collaborations with ornithologists and mammalogists should help reach this objective. The detailed comparison between primates and other frugivores should focus on various aspects of the seed dispersal process such as fruit traits (Flörchinger et al. 2010; Gautier-Hion et al. 1985), seed removal (Gross-Camp et al. 2009; Lambert 2011), seed germination (Fuzessy et al. 2016), seed dispersal distances (Clark et al. 2005; Fuzessy et al. 2017), and post-dispersal seed fate (Culot et al. 2017; Lugon et al. 2017; McConkey et al. 2015). The formal inclusion of these data into the seed dispersal effectiveness (SDE) framework (Culot et al. 2015; Schupp et al. 2010) will enable the evaluation of the relative contribution of primates as seed dispersal agents in the ecosystem. 
New technologies, such as more advanced and more efficient GPS devices, together with new analytical tools and paradigms to study animal movements (Nathan et al. 2008) as well as the availability of phylogenetic tools to include evolutionary perspectives (Razafindratsima and Dunham 2016), open new avenues for primatologists interested in studies of primate seed dispersal. Traditionally, the study of primates is usually done through primate follows with the detailed registration of their behavior and locations. Such data are rare in other animal groups. Coupling detailed behavioral and movement data with new statistical tools gives a unique opportunity to better understand primate use of space through movement modeling and infer the consequences for primate seed dispersal (see Bialozyt et al. 2014).

Finally, as clearly pointed out by Arroyo-Rodríguez and Fahrig (2014), there is an urgent need to adopt a landscape perspective in primate studies. If we want to predict the anthropogenic effects of habitat loss and forest fragmentation on the role of primates as seed dispersers, we need to collect data in areas of distinct fragmentation degree, which is also a challenging task if traditional methods are applied. A turning point will be reached in primate seed dispersal studies when we will be able to use new technologies and/or to adopt new approaches to deal with the difficulty of increasing the number of studied groups while still taking advantage of the detailed data obtained through traditional methods.

Acknowledgments We thank all the authors who contributed to this Special Issue and the reviewers whose comments have greatly improved the quality of the content of this Issue. We thank Joanna Setchell for approving our proposal and for providing comments that improved an earlier version of this manuscript. L. Culot received support from Fundação de Amparo à Pesquisa do Estado de São Paulo (FAPESP 2014/147390 ), and Y. Tsuji was financially supported by The Kyoto University Foundation.

\section{Compliance with ethical standards}

Conflict of Interest The authors declare no conflict of interest.

\section{References}

Andresen, E., Arroyo-Rodríguez, V., \& Ramos-Robles, M. (2018). Primate seed dispersal: old and new challenges. International Journal of Primatology. https://doi.org/10.1007/s10764-018-0024-Z.

Arroyo-Rodríguez, V., \& Fahrig, L. (2014). Why is a landscape perspective important in studies of primates? American Journal of Primatology, 76(10), 901-909.

Bialozyt, R., Flinkerbusch, S., Niggemann, M., \& Heymann, E. W. (2014). Predicting the seed shadows of a Neotropical tree species dispersed by primates using an agent-based model with internal decision making for movements. Ecological Modelling, 278, 74-84.

Chapman, C. A. (1995). Primate seed dispersal: Coevolution and conservation implications. Evolutionary Anthropology: Issues, News, and Reviews, 4(3), 74-82.

Chapman, C. A., \& Dunham, A. E. (2018). Primate seed dispersal and forest restoration: an African perspective for a brighter future. International Journal of Primatology.

Clark, C., Poulsen, J., Bolker, B., Connor, E., \& Parker, V. (2005). Comparative seed shadows of bird-, monkey-, and wind-dispersed trees. Ecology, 86(10), 2684-2694.

Culot, L., Bello, C., Batista, J. L. F., Couto, H. T. Z., \& Galetti, M. (2017). Synergistic effects of seed disperser and predator loss on recruitment success and long-term consequences for carbon stocks in tropical rainforests. Scientific Reports, 7(1), 7662. 
Culot, L., Huynen, M.-C., \& Heymann, E. W. (2015). Partitioning the relative contribution of one-phase and two-phase seed dispersal when evaluating seed dispersal effectiveness. Methods in Ecology and Evolution, 6, 176-186.

Culot, L., Huynen, M.-C., \& Heymann, E. W. (2018). Primates and dung beetles: two dispersers are better than one in secondary forest. International Journal of Primatology. https://doi.org/10.1007/s10764-018-0041-y.

Eisenberg, J. F., \& Thorington Jr., R. W. (1973). A preliminary analysis of a Neotropical mammal fauna. Biotropica, 5(3), 150-161.

Flörchinger, M., Braun, J., Böhning-Gaese, K., \& Schaefer, H. M. (2010). Fruit size, crop mass, and plant height explain differential fruit choice of primates and birds. Oecologia, 164(1), 151-161.

Fuzessy, L. F., Cornelissen, T. G., Janson, C., \& Silveira, F. A. (2016). How do primates affect seed germination? A meta-analysis of gut passage effects on Neotropical plants. Oikos, 125(8), 1069-1080.

Fuzessy, L. F., Janson, C. H., \& Silveira, F. A. (2017). How far do Neotropical primates disperse seeds? American Journal of Primatology, 79(7), 1-6.

Garber, P. A., \& Lambert, J. E. (1998). Introduction to primate seed dispersal. American Journal of Primatology, 45, 3-8.

Gautier-Hion, A., Duplantier, R., Quris, R., Feer, F., Sourd, C., et al (1985). Fruit characters as a basis of fruit choice and seed dispersal in a tropical forest vertebrate community. Oecologia, 65, 324-337.

Gross-Camp, N. D., Mulindahabi, F., \& Kaplin, B. A. (2009). Comparing the dispersal of large-seeded tree species by frugivore assemblages in tropical montane Forest in Africa. Biotropica, 41(4), 442-451.

Howe, H. F., \& Smallwood, J. (1982). Ecology of seed dispersal. Annual Review of Ecology and Systematics, $13,201-228$.

Lambert, J. E. (2011). Primate seed dispersers as umbrella species: a case study from Kibale National Park, Uganda, with implications for Afrotropical forest conservation. American Journal of Primatology, 73(1), 9-24.

Lugon, A. P., Boutefeu, M., Bovy, E., Vaz-de-Mello, F. Z., Huynen, M.-C., Galetti, M., \& Culot, L. (2017). Persistence of the effect of frugivore identity on post-dispersal seed fate: Consequences for the assessment of functional redundancy. Biotropica, 49(3), 293-302.

McConkey, K. R. (2018). Seed dispersal by primates in Asian habitats: from species, to communities, to conservation. International Journal of Primatology. https://doi.org/10.1007/s10764-017-0013-7.

McConkey, K. R., \& Brockelman, W. Y. (2011). Nonredundancy in the dispersal network of a generalist tropical forest tree. Ecology, 92(7), 1492-1502.

McConkey, K. R., Brockelman, W. Y., Saralamba, C., \& Nathalang, A. (2015). Effectiveness of primate seed dispersers for an "oversized” fruit, Garcinia benthamii. Ecology, 96(10), 2737-2747.

Nathan, R., Getz, W. M., Revilla, E., Holyoak, M., Kadmon, R., Saltz, D., \& Smouse, P. E. (2008). A movement ecology paradigm for unifying organismal movement research. Proceedings of the National Academy of Sciences of the USA, 105(49), 19052-19059.

Nevo, O., \& Valenta, K. (2018). The ecology and evolution of fruit odor: Implications for primate seed dispersal. International Journal of Primatology. https://doi.org/10.1007/s10764-018-0021-2.

Razafindratsima, O. H., \& Dunham, A. E. (2016). Frugivores bias seed-adult tree associations through nonrandom seed dispersal: A phylogenetic approach. Ecology, 97(8), 2094-2102.

Razafindratsima, O. H., Gentles, A., Drager, A. P., Razafimahaimodison, J.-C., Razalazampirenena, C. J., \& Dunham, A. E. (2018). Consequences of lemur loss for above-ground carbon stocks in a Malagasy rainforest. International Journal of Primatology. https://doi.org/10.1007/s10764-018-0042-x

Sato, H. (2018). Predictions of seed shadows generated by common brown lemurs (Eulemur fulvus) and their relationship to seasonal behavioral strategies. International Journal of Primatology.

Schupp, E. W., Jordano, P., \& Gómez, J. M. (2010). Seed dispersal effectiveness revisited: A conceptual review. New Phytologist, 188, 333-353.

Terborgh, J. W., Pitman, N., Silman, M., Schichter, H., \& Nunez, P. (2002). Maintenance of tree diversity in tropical forests. In A. J. Dennis, R. J. Green, E. W. Schupp, \& D. A. Westcott (Eds.), Seed dispersal: Theory and its application in a changing world (pp. 1-17). New York: CABI.

Tsuji, Y., \& Su, H.-H. (2018). Macaques as seed dispersal angets in Asian forests: a review. International Journal of Primatology. https://doi.org/10.1007/s10764-018-0045-7

Valenta, K., Nevo, O., \& Chapman, C. A. (2018). Primate fruit color: useful concept or alluring myth? International Journal of Primatology. https://doi.org/10.1007/s10764-018-0025-y.

Wang, B. C., \& Smith, T. B. (2002). Closing the seed dispersal loop. Trends in Ecology and Evolution, 17(8), 379-385. 